\title{
BENEFÍCIOS DO MEL E PÓLEN DE FORRAGEIRAS NOS PARÂMETROS BIOLÓGICOS DE CHRYSOPERLA EXTERNA (HAGEN, 1861) (NEUROPTERA: CHRYSOPIDAE)
}

\author{
S.A. Oliveira ${ }^{1 *}$, A.M. Auad ${ }^{2}$, B. Souza ${ }^{1}$, C.A. Carvalho ${ }^{2}$, L.S. Souza ${ }^{3}$, R.L. Amaral ${ }^{4}$, D.M. Silva ${ }^{3}$
}

${ }^{1}$ Universidade Federal de Lavras, CP 3037, CEP 37200-000, Lavras, MG, Brasil. E-mail: sibiojf@yahoo.com.br

\begin{abstract}
RESUMO
Objetivou-se avaliar o benefício do mel e do pólen proveniente de duas espécies de forrageiras, sobre os aspectos biológicos da fase adulta de Chrysoperla externa (Hagen, 1861). Casais do predador foram individualizados em gaiolas cilíndricas de PVC $(10 \times 10 \mathrm{~cm})$ mantidas em câmaras climatizadas a $25 \pm 1^{\circ} \mathrm{C}, 70 \%$ UR e fotofase de 12 horas. Utilizaram-se dietas à base de lêvedo de cerveja + mel (1:1) e pólen de mamona com e sem adição de mel (testemunhas) e os seguintes tratamentos: pólens de capim-elefante, braquiária, capim-elefante + mel e braquiária + mel. Quando foi fornecido apenas pólen de mamona, os crisopídeos apresentaram o menor tempo de vida e não realizaram posturas. Os períodos de pré-oviposição e oviposição não foram influenciados pelas diferentes fontes de alimento com a presença de mel, independente da fonte proteica. O número de ovos / fêmea foi maior para a dieta com lêvedo de cerveja + mel, seguida dos pólens de capim-elefante + mel, mamona + mel e braquiária + mel. Verificou-se que o pólen das plantas apresentou efeitos positivos sobre a biologia de C. externa, quando adicionado mel como fonte de carboidrato. Portanto, para maior eficiência e permanência deste inimigo natural em cultivos dessas forrageiras, recomenda-se a suplementação alimentar com flores ou outras fontes de obtenção de carboidratos.
\end{abstract}

PALAVRAS-CHAVE: Biologia, crisopídeos, dieta alimentar, forrageira.

\section{ABSTRACT}

BENEFITSOFHONEY ANDPOLLENOFFORRAGEONTHE BIOLOGICALPARAMETERSOF CHRYSOPERLA EXTERNA (HAGEN, 1861) (NEUROPTERA: CHRYSOPIDAE). Investigations were carried out of the benefits of honey and pollen of two forage species on biological aspects of the adult phase of Chrysoperla externa (Hagen, 1861). Mating pairs of the predator were placed in cylindrical PVC cages $(10 \mathrm{~cm} \times 10 \mathrm{~cm})$ and maintained in climate-controlled chambers at $25 \pm$ $1^{\circ} \mathrm{C}, 70 \% \mathrm{RH}$ and 12 -hour photophase. They were fed diets of yeast + honey (1:1) and castor pollen without the addition of honey (controls), and the following treatments: elephant grass pollen; signal grass pollen; elephant grass pollen + honey; signal grass pollen + honey. When they were only given castor pollen, the green lacewings had shorter life spans and did not lay eggs. The prelaying and laying periods were not influenced by the different food sources with the presence of honey, regardless of the protein source. The number of eggs/female was greater for the diet with yeast + honey (1:1), followed by elephant grass pollen + honey, castor pollen + honey, and signal grass + honey. It was found that the pollen of the tested plants had positive effects on the biology of C. externa, when honey was added as a carbohydrate source. Therefore, to aid the performance and permanence of this natural pest predator in these forage crops, it is recommended that the lacewings' food be supplemented with flowers or other sources of carbohydrates.

KEY WORDS: Biology, diet, forage, green lacewing.

\section{INTRODUÇÃO}

Nas condições brasileiras, Chrysoperla externa (Hagen,1861)éuma das espécies deNeuroptera mais frequentes (SouZA,1999; FonsECAetal., 2000). A grande capacidade de busca, voracidade das larvas, elevado potencial reprodutivo e facilidade de criação em laboratório a torna predador chave em muitos sistemas

${ }^{2}$ Embrapa Gado de Leite, Juiz de Fora, MG, Brasil.

${ }^{3}$ UNIPAC/Juiz de Fora, MG, Brasil.

${ }^{4}$ Universidade Federal de Juiz de Fora, Juiz de Fora, MG, Brasil.

*Doutoranda em Agronomia/Entomologia - Universidade Federal de Lavras. 
agrícolas e potencializa sua utilização em programas de controle biológico (CARVALHO; SOUZA, 2000).

A diversificação de plantas em um ecossistema pode favorecer a presença dos crisopídeos, por proporcionar condições adequadas à sua permanência. Essa estratégia oferece proteção e fonte de alimento aos adultos que são consumidores de pólen, néctar e honeydew (New, 1988; StelzL; DevetaK, 1999; LANDis et al., 2000; GuRR et al., 2003).

Os parâmetros biológicos dos insetos podem ser afetados por diversos fatores, sendo a fonte alimentar uns dos mais importantes. TAUBER; TAUBER (1974) relataram que a dieta consumida pode, direta ou indiretamente, alterar as glândulas endócrinas, refletindo no comportamento, na cópula e na oviposição. BOREGAS et al. (2003) mencionaram que diferentes respostas na biologia desses neurópteros podem ser devido às diferenças na composição dos pólens, que são extraídos de várias espécies de vegetais, afetando sua fisiologia. Segundo PANnIzI; PARRA (1991), os tipos de pólen variam em relação à sua constituição e podem apresentar mais de 14 carboidratos que participam ativamente da geração de energia e síntese proteica nos insetos. Roulston; CANE (2000) explicaram que o pólen possui acima de $60 \%$ de proteína e, geralmente, ébemaceitona alimentação animal, apresentando alta digestibilidade.

C. externa apresenta exigências nutricionais qualitativas queenvolvem proteínas, aminoácidos essenciais, carboidratos, açúcares simples, vitaminas e sais minerais para o desenvolvimento normale manutenção da fecundidadee fertilidade (HAGEN; TASSAN, 1970; House, 1977). Sabendo-se que elevadas populações desses predadores estão presentes em gramíneas forrageiras alimentando-sede pólen(AuADetal.,2001), faz-se necessário conhecer a relação desse predador com essa fonte proteica. Desta forma, o objetivo do trabalho foi verificar o benefício do mel e do pólen provenientes de forrageiras, sobre os aspectos biológicos de adultos de C. externa.

\section{MATERIALEMÉTODOS}

Adultos de C. externa, geração $\mathrm{F}_{4^{\prime}}$ provenientes do Departamento deEntomologia da Universidade Federal de Lavras/UFLA, foram sexados e, posteriormente, acondicionado um casal por gaiola de PVC ( $10 \mathrm{~cm}$ de diâmetrox $10 \mathrm{~cm}$ dealtura). No Laboratório de Entomologia da Embrapa/ Gado de Leite, os insetos foram mantidos em câmaras climatizadas a $25 \pm 1^{\circ} \mathrm{C}, 70 \%$ UR e fotofase de 12 horas. As gaiolas foram revestidas com papel filtro branco, que serviu como substrato de oviposição, e as extremidades superior e inferior foram fechadas com tecido tipo voil.
Foram oferecidas as dietas: 1- lêvedo de cerveja + mel (1:1); 2- pólen de capim-elefante , 3- pólen de braquiária ; 4- pólen de mamona; 5- pólen de capimelefante + mel; 6- pólen debraquiária + mele,7-pólen de mamona + mel. Opólen, obtido a partir de plantas do Campo Experimental da Embrapa Gado de Leite, era mantido em refrigerador $\left(4^{\circ} \mathrm{C}\right)$. Considerou-se a dieta constituída por lêvedo de cerveja + mel como tratamento controle, por ser a mistura normalmente usada em laboratórios de criação de crisopídeos. O pólen de mamona, o qual já se mostrou nutricionalmente adequado para outras espécies de crisopídeos (Krishnamoorthy, 1984; GaUtam; PAUL, 1988) também foi incluído como tratamento testemunha. As dietas e a água foram oferecidas em tampas de Eppendorf e renovadas a cada três dias. Foram utilizadas 10 repetições, perfazendo um total de 70 parcelas.

A cada três dias, os ovos de C. externa, eram removidos do substrato com o auxílio de estilete e contabilizados. Para o estudo da viabilidade e período embrionário, cinco ovos eram retirados do total de cada coleta e de cada gaiola, separadamente. Estes eram acondicionados em placas tipo Elisa emantidos a $25^{\circ} \mathrm{C}, \mathrm{UR} 70 \%$ e fotofase de 12 horas, por um período de 10 dias.

Foram avaliados os parâmetros: períodos de préoviposição, oviposiçãoe pós-oviposição,longevidade de machos e fêmeas, capacidade de oviposição total e diária, período embrionário e viabilidade dos ovos.

Para análise dos dados usou-se o teste não paramétrico de Kruskal-Wallis e Dunn, em níveis de significância de $5 \%$.

\section{RESULTADOSEDISCUSSÃO}

Alongevidadedemachose fêmeas deC.externa foi maior quando alimentada com lêvedo de cerveja + mel,pólen decapim-elefante + melepólen demamona + mel, com variação de 39 a 45 dias para os machos e de 73 a 78 dias para as fêmeas (Tabela 1). Verificou-se que as dietas sem adição de mel, acarretaram uma longevidade significativamentemenor, exceção feita àquela composta de braquiária + mel, que apesar de ser suplementada com essa fonte de carboidratos, não proporcionou aumento na longevidade de machos e fêmeas em relação às demais. Quando foi fornecido apenas pólen de mamona, os adultos apresentaram o menor tempo de vida, 6,4 e 8,3 dias, para machos e fêmeas, respectivamente. Resultados obtidos por VeNZON et al. (2006), com essa mesma espécie de crisopídeo, foram semelhantes aos constatados no presente trabalho, verificando que dietas acrescidas demel proporcionaram maior longevidade. McEWEN; KIDD (1995) verificaram aumento significativo na 
duração do tempo de vida de Chrysoperla carnea Stephens (1836) quando foi acrescentado açúcar na dieta dos adultos e KRISHNAMOORTHY (1984) também registrou para Brinckochrysa scelestes (Banks, 1911) (=Chrysopa scelestes) alimentados com pólen de mamona + mel, maior longevidade em relação às dietas sem adição deste carboidrato. No entanto, Boregas et al. (2003) e RiBEIRO et al. (1993), trabalhando com C. externa, e Venzon; Carvalho (1992) com Ceraeochysa cubana (Hagen, 1861), verificaram que o consumo de diferentes dietas, independente da adição de mel, não interferiu na longevidade dos insetos.

Os períodos de pré-oviposição e oviposição não foram influenciados pelo alimento oferecido (Tabela 1), resultados que se assemelham àqueles obtidos por BOREgAs et al. (2003) e VENZON et al. (2006) para C. externa supridas com diferentes dietas à base de pólen emel. VENZON; CARVALHO (1992) tambémnão observaram diferenças no período de oviposição de C. cubana em função das diferentes dietas ofertadas.

De acordo com Ribeiro (1988) e Gautam; PaUl (1988), o período de pré-oviposição, geralmente, é influenciado pela alimentação dos crisopídeos, sendo reduzido quando a dieta contém carboidratos e proteínas. KRISHNAMOORTHY (1984) registrou para $B$. scelestes um menor período de pré-oviposição com dieta à base de "honeydew" + pólen de mamona, em relação àquela constituída somente por mel.Portanto, quando foi oferecida uma dieta composta por proteínas e carboidratos, houve uma resposta biológica evidenciada pela redução do período de préoviposição, o que corrobora os resultados do presente estudo.

Em relaçãoà fecundidade, verificou-sequefêmeas de C. externa alimentadas com pólens de mamona, braquiária e capim-elefante, não ovipositaram. MCEWEN;KIDD (1995) também verificaram queonúmero total de ovos/fêmea, bem como a média diária de ovos produzidos, foram maiores para adultos de $C$. carnea alimentados comlêvedoe açúcar; entretanto, as fêmeas não ovipositaram quandoesses componentes foram fornecidos separadamente. Os autores mencionaram a importância, não apenas de proteínas na composição da dieta dos crisopídeos, mas também a associação com açúcares, visando a um aumento da fecundidade desses insetos. BOREGAs et al. (2003) também não observaram posturas quando forneceram apenas lêvedo de cerveja para adultos de C. externa. Krishnamoorthy (1984) e GAUtam; PAUL (1988) verificaram incremento na fecundidade ao adicionarem mel ao pólen de mamona oferecido a B. scelestes. Da mesma forma, VENZON et al. (2006) constataram que, provavelmente, $C$. externa necessite de uma maior concentração de carboidratos do que o encontrado nos pólens para expressarem todo seu potencial reprodutivo.

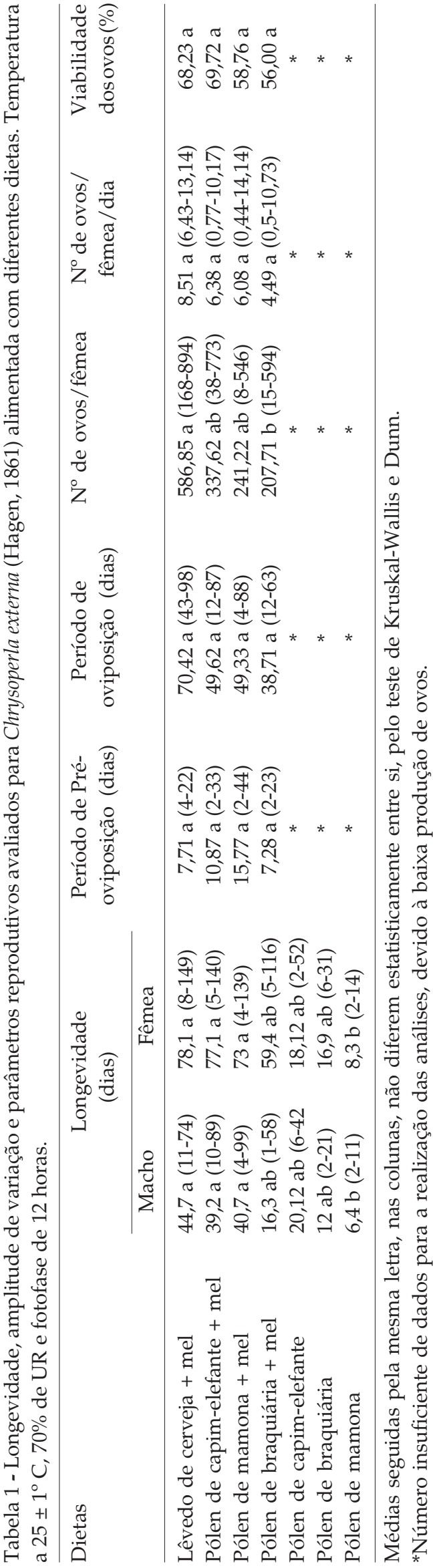

Arq. Inst. Biol., São Paulo, v.76, n.4, p.583-588, out./dez., 2009 
TOOD; BRETHERICK (1942) argumentaram que o baixo teor de carboidratos no pólen condiciona à necessidade da adição de mel para o aumento do sucesso reprodutivo dos insetos. Desta forma, a baixa fecundidade deC.externa registrada no presente estudo, para dietas desprovidas de mel, pode ser consequência da ausência dessa fonte de carboidrato na sua alimentação.

O número de ovos/fêmea foi maior quando alimentadas com lêvedo de cerveja + mel (587 ovos/ fêmea), seguidos de pólen de capim-elefante + mel (338 ovos/fêmea) e pólen de mamona + mel (241 ovos/fêmea)(Tabela1).Ummenornúmerodeovosfoi produzido quando os insetos se alimentaram com pólen de braquiária + mel (208 ovos / fêmea), deve-se ressaltar que a longevidade das fêmeas alimentadas com essa dieta também foi significativamente menor; resultados que proporcionaram uma produção média diária próxima àquelas obtidas para as demais dietas oferecidas. Não foi verificada diferença significativa na porcentagem de eclosão de larvas (Tabela 1), resultados que se assemelharam àqueles obtidos por VENZON et al. (2006), que também não registraram diferenças na viabilidade de ovos de C. externa alimentada com diferentes fontes de pólen.

A dieta constituída por lêvedo de cerveja + mel (1:1) é amplamente utilizada em criações de crisopídeos em laboratório e diversos estudosjá relataram sua importância nutricional para o desenvolvimento da fase adulta destes neurópteros. No presente estudo, o pólen de capim-elefante + mel foi a dieta que proporcionou uma produção de ovos mais próxima às registradas para lêvedo de cerveja + mel e pólen de mamona + mel (dietas consideradas neste estudo como tratamentos controle), o que denota a qualidade do pólen dessa forrageira.

Os resultados desse estudo corroboram com outros que enfatizam a importância da associação de proteína e carboidratos na composição do alimento dos crisopídeos. Venzonet al. (2006) verificaram acentuado aumento na oviposição de C. externa alimentada com dieta composta por pólen e mel em relação àquelas supridas com apenas pólen. Da mesma forma, RiBEIRO (1988) verificou maior produção de ovos de C. externa alimentada com dieta constituída por pólen e mel. KRISHNAMOORTHY (1984) também constatou que a adição de mel à dieta de pólen de mamona proporcionou aumentono número diário de ovosena fecundidade total de B. scelestes.

Observou-se que a maior produção de ovos de $C$. externa, $80 \%$ dos ovos coletados, ocorreu entre o $13^{\circ} \mathrm{e}$ o $45^{\circ}$ dias de vida (Fig. 1). Essa informação facilita as criações de crisopídeos em laboratório, por evidenciar a época de se proceder ao descarte de adultos, ou seja, a eliminação dos insetos do processo de produção, por se tornarem economicamente inviáveis (CARVALHO; SOUZA, 2000). Contabilizaram-se ovos oriundos de fêmeas alimentadas com lêvedo de cerveja + mel em todo o período de avaliação, exceto três dias após o início da postura. Ovos do predador estiveram presentes em 90, 67 e 86\% das coletas, porém em número reduzido, quando se ofertou aos adultos pólens de capim-elefante, braquiária ou mamona adicionados ao mel. Devido ao fato da baixa longevidade dessas fêmeas, somente em 14 e $21 \%$ das amostras tiveram ovos provenientes de adultos alimentados com pólen de braquiária e capim-elefante sem adição do mel (Fig. 1).

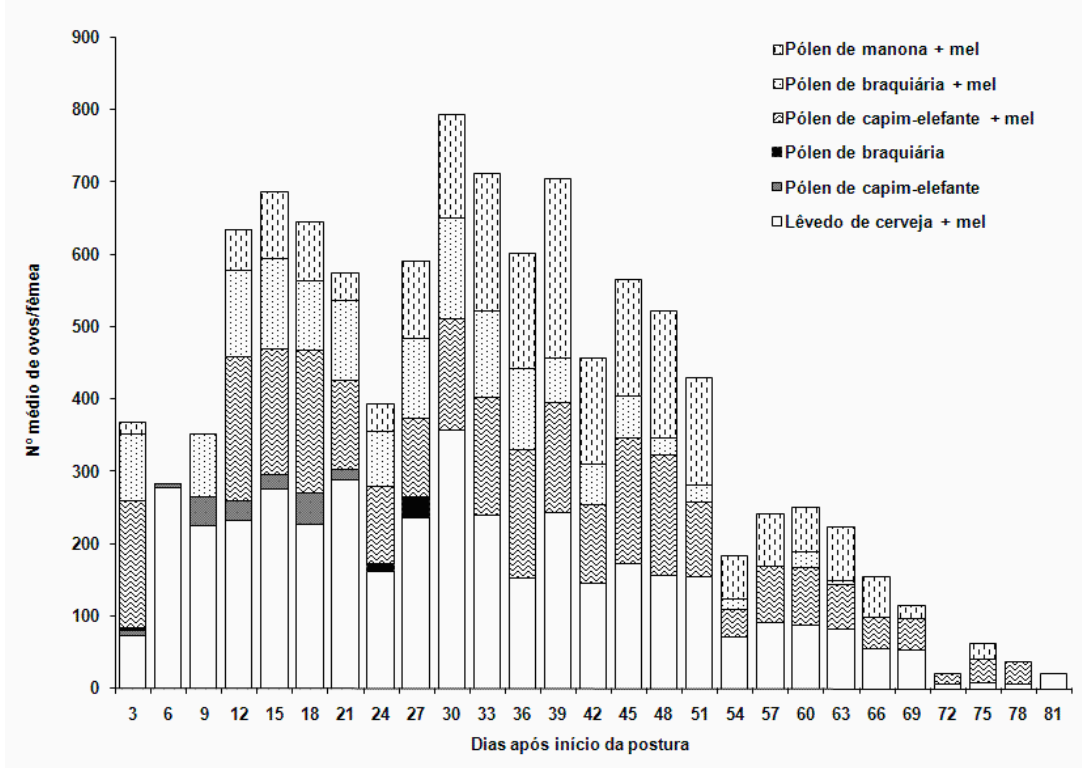

Fig. 1 - Número médio de ovos / fêmea de Chrysoperla externa (Hagen, 1861) criadas em dietas à base de levêdo-de-cerveja, pólen e mel. Juiz de Fora, MG. 
Os resultados evidenciaram que o pólen das forrageiras é um importante constituinte protéico na dieta de $C$. externa, se associado a fontes de carboidratos, como o mel. Para a conservação e aumento da eficiência desse predador em condições naturais há necessidade de enriquecer a flora associada com flores ou outras fontes de obtenção de carboidratos como suplemento na dieta desses insetos.

\section{CONCLUSÃO}

O pólen das forrageiras, capim-elefante e braquiária, constituem-se em uma fonte protéica alternativa para adultos de C. externa; porém, a efetividade dessa dieta na biologia reprodutiva da espécie é incrementada com a suplementação de mel como fonte de carboidrato.

\section{AGRADECIMENTOS}

À FAPEMIG pela bolsa concedida para a doutoranda, à EMBRAPA/Gado de Leite por ceder o espaço para a realização dos experimentos.

\section{REFERÊNCIAS}

AUAD, A.M.; TOSCANO, L.C.; BOIÇA JÚNIOR, A.L.; FREITAS, S. DE. Aspectos biológicos dos estádios imaturos de Chrysoperla externa (Hagen) e Ceraeochrysa cincta (Schneider) (Neuroptera: Chrysopidae) alimentados com ovos e ninfas de Bemisia tabaci (Gennadius) biótipo B (Hemiptera: Aleyrodidae). Neotropical Entomology, v.30, n.3, p.429-432, 2001.

BOREGAS, K.G.B., CARVALJO, C.F.; SOUZA, B. Aspectos biológicos de Chrysoperla externa (Hagen, 1861) (Neuroptera: Chrysopidae) em casa-de-vegetação. Ciência Agrotecnica, v.27, n.1, p.7-16, 2003.

CARVALHO, C.F.; SOUZA, B. Métodos de criação e produção de crisopídeos. In: BUENO V.H.P. (Ed). Controle biológico de pragas: produção massal e controle de qualidade. Lavras: Editora Ufla, 2000. cap.6, p.91-110.

FONSECA, A.R.; CARVALHO, C.F.; SOUZA, B. Resposta funcional de Chrysoperla externa (Hagen)

(Neuroptera: Chrysopidae) alimentada com Schizaphis graminum (Rondani) (Hemíptera: Aphididae). Anais da Sociedade Entomológica do Brasil, v.29, n.2, p.309-317, 2000.

GAUTAM, R.D.; PAUL, A.V.N. Influence of adult food suplements on Chrysopa scelestes Banks (Chrysopidae: Neuroptera). Journal of Entomological Research, v.12, p.2527, 1988.
GURR, G.M.; WRATTEN, S.D.; LUNA, J.M. Multifunction agricultural biodiversity: Pest management and other benefits. Basic and Applied Ecology, v.4, n.2, p.107-116, 2003.

HAGEN, K.S.; TASSAN, R.L. The influence of food wheast and related Saccharomyces fragilis yeast products on the fecundity of Chrysoperla carnea (Neuroptera: Chrysopidae). Canadian Entomologist, v.86, p.315-320, 1970.

HOUSE, H.L. Nutrition of natural enemies. In: RIDGWAY, R.L.; VINSON, S.B. (Ed.). Biological control by augmentation of natural enemies. New York: Plenum Press, 1977. p.151-182.

KRISHNAMOORTHY, A. Influence of adult diet on the fecundity and survival of the predator, Chrysopa scelestes (Neur.: Chrysopidae). Entomophaga, v.29, n.4, p.445-450, 1984.

LANDIS, D.A., WRATTEN, S.D.; GURR, G.M. Habitat management to conserve natural enemies of arthropod pests in agriculture. Annual Review of Entomology, v.45, p.175-201, 2000.

MCEWEN, P.K.; KIDD, N.A.C. The effects of different components of an artificial food on adult green lacerwing (Chrysoperla carnea) fecundity and longevity. Entomologia Experimentalis et Applicata, v.77, p.343-346, 1995.

NEW, T.R. Neuroptera.. In: MINKS, A.K.; HARREWIJN, P. (Ed.). Aphids, their biology, natural enemies and control. Amsterdan: Elsevier, 1988. v.2B, p.249-258.

PANIZZI, A.R.; PARRA, J.R.P. Ecologia nutricional de insetos e suas implicações no manejo de pragas. São Paulo: Manole, 1991. 359p.

RIBEIRO, M.J. Biologia de Chrysoperla externa (Hagen) (Neuroptera: Chrysopidae) alimentada com diferentes dietas. 1988. 131p. Dissertação (Mestrado em Agronomia Área de Fitossanidade) - Universidade Federal de Lavras, Lavras, 1988.

RIBEIRO, M.J.; CARVALHO, C.F.; MATIOLI, J.C. Biologia de adultos de Chrysoperla externa (Hagen, 1861) (Neuroptera: Chrysopidae) em diferentes dietas artificiais. Ciência e Prática, v.17, n.2, p.120-130. 1993.

ROULSTON, T.H.; CANE, J.H. Pollen nutritional content and digestibility for animals. Plant Systematics and Evolution, v.222, n.1/4, p.187-209, 2000.

SOUZA, B. Estudos morfológicos do ovo e da larva de Chrysoperla externa (Hagen, 1861) (Neuroptera: Chrysopidae) e influência de fatores climáticos sobre a flutuação populacional de adultos em citros. 1999. 141f. Tese (Doutorado em Agronomia) - Escola Superior de Agricultura de Lavras, Lavras, 1999. 
STELZL, M.; DEVETAK, D. Neuroptera in agricultural ecosystems. Agriculture, Ecosystems Environment, v.74, n.1-3, p.305-321, 1999.

TAUBER, M.J.; TAUBER, C.A. Thermal accumulations, diapause, and oviposition in a conifer-inhabiting predador, Chrysopa harrisii (Neuroptera). Canadian Entomologist, v.106, p.969-978. 1974.

TOOD, F.E.; BRETHERICK, O. The composition of pollens. Journal of Economic Entomology, v.35, n.3, p.312317.1942.

VENZON, M.; CARVALHO, C.F. Biologia da fase adulta de Ceraeochysa cubana (Hagen, 1861)
(Neuroptera, Chrysopidae) em diferentes dietas e temperaturas. Ciência e Prática, v.16, n.3, p.315-320. 1992.

VENZON, M.; ROSADO, M.C.; EUZÉBIO, D.E.; SOUZA,B.; SCHOEREDER, J.H. Suitability of leguminous cover crop pollens as food source for the green lacerwing Chrysoperla externa (Hagen) (Neuroptera: Chrysopidae). Neotropical Entomology, v.35, n.3, p.371-376, 2006.

Recebido em 15/7/08

Aceito em 14/5/09 